\title{
RECURSOS EDUCACIONAIS ABERTOS: SEUS CONCEITOS E SUAS LICENÇAS CREATIVE COMMONS
}

Ana Paula Ambrósio Zanelato Marques, Carla Plantier Message, Adriana Aparecida de Lima Terçariol

Universidade do Oeste Paulista - UNOESTE, Mestrado em Educação, Presidente Prudente - SP. E-mail: anapaulazanelato@gmail.com

\section{RESUMO}

Este artigo tem como propósito descrever a importância dos Recursos Educacionais Abertos (REA) e suas licenças de uso. As pesquisadoras propuseram-se a conceituar os REA, identificando os tipos de licenças Creative Commons utilizados para divulgação dos materiais. Além disso, pretende-se descrever como encontrar e compartilhar materiais educacionais, exemplificando por meio de sites e repositórios disponíveis na internet. Para tal objetivo, utilizamos como metodologia a pesquisa bibliográfica onde autores desta área fundamentam sobre o tema em questão. Portanto, conclui-se que REA disponibiliza material licenciado, e que contribui para o desenvolvimento colaborativo de conteúdos de aprendizagem. Além disso, necessita-se de políticas públicas que apoiem e incentivem sua utilização.

Palavras-Chave: Recursos Educacionais Abertos; Licenças Creative Commons; Repositórios; Educação Aberta; Materiais Educacionais.

\section{OPEN EDUCATION RESOURCES: CONCEPTS AND THEIR LICENCES CREATIVE COMMONS}

\section{ABSTRACT}

This paper discuss the importance of Open Education Resources (OER) and its use licenses. The researchers conceptualize OER, identifying the types of Creative Commons licenses used for dissemination of materials. Besides that, it is intended to describe how to find and share educational materials, exemplifying through sites and repositories available on the internet. For this purpose, we use a methodology the literature where authors of this area are based on the topic in question. So, it is concluded that OER offers licensed materials, and contributes to the collaborative development of learning content. Besides that, requires public policies that support and encourage their use.

Keywords: Open Education Resources; Creative Commons license; Repositories; Open Education; Education Materials; 


\section{INTRODUÇÃO}

O termo Educação Aberta é utilizado em vários contextos, envolvendo práticas tradicionais e outras mais recentes, porém todas relacionadas a um processo de aprendizagem, sem imposições ou regras de quem ensina.

O movimento para uma Educação Aberta é uma tentativa de buscar alternativas sustentáveis para algumas das barreiras evidentes no que tange ao direito de uma educação de qualidade. Nessa perspectiva, o conceito de "abertura" não é necessariamente dependente de desenvolvimentos tecnológicos, e antecede a popularização de dispositivos digitais, da internet e da web, mas pode ser fortalecida por novas mídias (SANTANA; ROSSINI; PRETTO, 2012, p. 18).

Atualmente, a Educação Aberta é vinculada aos chamados Recursos Educacionais Abertos, trazendo novas práticas de ensino-aprendizagem com utilização das tecnologias educacionais, porém, não é exclusiva, a utilização dos Recursos Educacionais Abertos é mais uma forma de se fazer Educação Aberta.

O termo Recursos Educacionais Abertos foi citado pela primeira vez pela UNESCO, em 2002, e pode ser definido como

[...] materiais de ensino, aprendizado e pesquisa, fixados em qualquer suporte ou mídia, que estejam sob domínio público ou licenciados de maneira aberta, permitindo que sejam utilizados ou adaptados por terceiros. Os Recursos Educacionais Abertos são como blocos que podem ser conectados por pessoas diferentes, em locais diferentes e modos diferentes, para satisfazer uma necessidade específica do conhecimento (SEBRIAN, 2013, p. 01).

“[...]São considerados conteúdos abertos os materiais disponíveis na internet sob licença específica como artigos, cursos, aulas, imagens, vídeos, áudios, softwares com códigos abertos, entre outros materiais com características de auxílio no processo de ensino e de aprendizagem. "(GITAHY et al., 2015, p. 1491).

Este artigo busca conceituar os Recursos Educacionais Abertos e suas licenças de uso, identificando os tipos existentes de licenças para divulgação dos materiais. Além disso, pretendese descrever como encontrar e compartilhar materiais educacionais, exemplificando por meio de sites e repositórios disponíveis na internet.

\section{METODOLOGIA}

Para a realização deste estudo foram utilizados procedimentos metodológicos próprios das pesquisas bibliográficas. Através da investigação bibliográfica, considerada por Vergara (1998, p. 46), como aquela que "é estudo sistematizado desenvolvido com base em material publicado em livros, revistas, jornais, redes eletrônicas, isto é, material acessível ao público em geral", com base na qual foi empreendida a revisão de literatura que possibilitou a fundamentação teórica sobre a temática do estudo.

\section{DISCUSSÃO}

\section{RECURSOS EDUCACIONAIS ABERTOS}

Em 2002, foi lançado um projeto chamado de OpenCourseWare (OCW) pelo Massachusetts Institute of Tecnology (MIT) que possuía como objetivo a publicação aberta de 50 cursos na internet para promover o conhecimento de educar estudantes. Com o passar dos anos, mais cursos foram publicados, com visitas de estudantes de diversos países. No mesmo ano, analisando 
esta iniciativa, a UNESCO promoveu um fórum educacional, neste evento surgiu o termo Open Educational Resources (OER). A partir de então, a comunidade de Recursos Educacionais Abertos tem se esforçado para produzir materiais educacionais de alta qualidade para professores e alunos, das mais diversas áreas de conhecimento.

Segundo a comunidade Recursos Educacionais Abertos Brasileira ${ }^{1}$, apoiada nas definições da UNESCO, REA pode ser definido como: "REA são materiais de ensino, aprendizado e pesquisa, fixados em qualquer suporte ou mídia, que estejam sob domínio público ou licenciados de maneira aberta, permitindo que sejam utilizados ou adaptados por terceiros."

Hilen apud Dutra;Tarouco (2007, p. 02) comenta que:

Os REA abrangem os Conteúdos de Aprendizagem, ou seja, cursos, módulos de conteúdo, objetos de aprendizagem entre outros. Eles incluem também ferramentas para apoiar o desenvolvimento, uso, reuso, busca e organização de conteúdos, bem como Sistemas de Gerenciamento de Aprendizagem e ferramentas de autoria. E por último os REA contemplam os chamados recursos de implementação que abrangem licenças para a disseminação de materiais abertos, bem como recursos de localização de conteúdos.

Desde então, esforços tem sido realizados para produzir e manter material educacional de alta qualidade, para professores e alunos das mais diversas áreas do conhecimento. Segundo a comunidade Recursos Educacionais.

Para entender como REA funciona, é necessário pensar como um "ciclo de vida", em que se inicia com uma necessidade do professor em aprender ou ensinar algo. A figura 1 ilustra este ciclo.

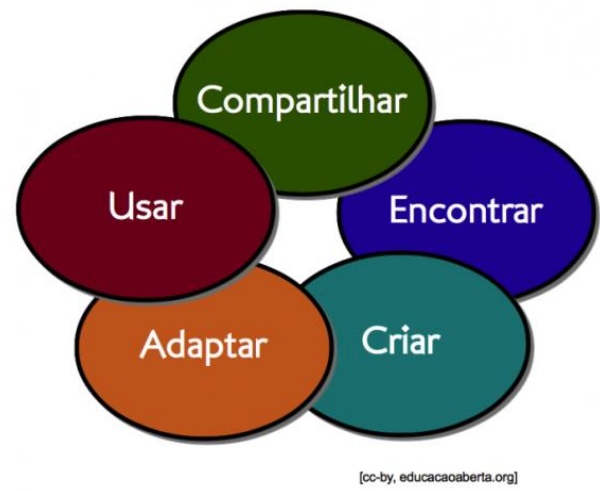

Fonte: Educação Aberta (2016).

As etapas do ciclo são:

- Encontrar: procurar por recursos que sejam adequados a sua necessidade.

- Criar: consiste em criar um novo recurso, ou combinar algum já existente, criando um novo.

- Adaptar: esse processo inclui melhoramentos, correções e contextualizações do material encontrado.

- Usar: consiste na utilização do material em sala de aula.

- Compartilhar: uma vez finalizado, o material poderá ser compartilhado, reiniciando o ciclo de vida.

\footnotetext{
${ }^{1}$ http://rea.net.
}

$\mathrm{br} / \mathrm{site}$ 


\section{LICENÇAS CREATIVE COMMONS}

Atualmente existe uma vasta quantidade de materiais disponíveis na internet, porém, boa parte desses materiais estão sob a licença dita como copy rigth, ou seja, todos os direitos são reservados aos autores do material. Para ofertar uma maneira padronizada de autorização dos direitos autorais foram criadas as licenças creative commons (CC).

Quando materiais didáticos e educacionais são considerados commons, bens públicos e comuns, todos podem se beneficiar: professores, estudantes e autores interessados na utilização de sua produção. Quando tais materiais são pagos com dinheiro público, seja pelos programas de incentivo ao livro e à leitura ou por iniciativas próprias de governos produzirem materiais, faz ainda mais sentido que sejam bens públicos. $\mathrm{E}$ por incentivarem a produção aberta, o compartilhamento e o acesso a conteúdos, os chamados recursos educacionais abertos otimizam a utilização de recursos públicos (ROSSINI apud SANTANA;ROSSINI;PRETTO, 2012, p.141).

Para um autor definir o seu trabalho com uma licença do tipo CC, primeiramente ele responde a um questionário no site creativecommons.org ou creativecommons.org.br. Após responder o questionário, será atribuído o tipo de licença que será utilizada, que são:

- CC BY: Permite a distribuição, remixagem, adaptação e criação a partir de um trabalho, mesmo para fins comerciais, atribuindo o crédito pela criação original. De todas as licenças, é a mais flexível. É recomendada para maximizar a disseminação e uso dos materiais licenciados.

- CC BY-SA: Permite a remixagem, adaptação e criação a partir do seu trabalho, mesmo comercialmente, atribuindo os créditos devidos e que as novas criações sejam licenciadas sob termos idênticos.

- CC BY-ND: Permite a distribuição comercial e não comercial, desde que o trabalho seja distribuído inalterado e no seu todo, com crédito atribuído ao autor.

- CC BY-NC: Permite remixagem, adaptação e criação a partir de um trabalho para fins não comerciais. Embora os novos trabalhos tenham que atribuir os devidos créditos e não possam ser usados comercialmente, os usuários não necessitam licenciar esses trabalhos derivados sob os mesmos termos.

- CC BY-NC-SA: Permite a remixagem, adaptação e criação a partir de um trabalho para fins não comerciais, desde que seja atribuído o devido crédito ao autor e que licencie as novas criações sob os mesmos termos.

- CC BY-NC-ND: Essa é a mais restritiva das licenças, permite o download e o compartilhamento, atribuindo o crédito ao autor, sem realizar qualquer alteração e também de uso não comercial.

Essas licenças CC podem ser ofertadas para qualquer tipo de material intelectual que requer licenciamento.

\section{COMO BUSCAR E COMPARTILHAR REA}

Além desses benefícios, os recursos educacionais abertos criam a oportunidade para uma transformação ainda mais fundamental na educação: a de envolver educadores e estudantes (e mesmo aqueles que não estejam formalmente vinculados a uma instituição de ensino) no processo criativo de desenvolver e adaptar recursos educacionais. Além de produzir material e incentivar diversas possibilidades de uso, governos e instituições de ensino podem formar professores e alunos para a produção 
colaborativa de textos, imagens e vídeos de qualidade. É criado espaço para a formação continuada de professores e estudantes, para a produção e edição de material didático e a apropriação de tecnologias digitais em seu cotidiano. Com a abertura dos materiais na rede, a possibilidade de formação continuada se expande a toda a sociedade (ROSSINI apud SANTANA; ROSSINI; PRETTO, 2012, p. 140).

Podemos encontrar e compartilhar REA em repositórios criados no Brasil e também em todo mundo, repositórios são bases de dados mantidas por instituições de ensino e pesquisa, onde os REA são depositados e indexados. Alguns repositórios mantém os REA com informações dos tipos de licenças creative commons. A tabela 1 ilustra alguns repositórios disponíveis no Brasil.

Tabela 01. Lista de alguns repositórios no Brasil

\begin{tabular}{|c|c|c|}
\hline Nome & Endereço & Conteúdo \\
\hline Biblioteca Digital Vérsila & $\begin{array}{l}\text { http://biblioteca.versila.com } \\
\text { / }\end{array}$ & $\begin{array}{l}\text { Educação básica, } \\
\text { superior, etc. }\end{array}$ \\
\hline $\begin{array}{l}\text { Banco Internacional de } \\
\text { Objetos Educacionais }\end{array}$ & $\begin{array}{l}\text { http://objetoseducacionais2. } \\
\text { mec.gov.br/ }\end{array}$ & $\begin{array}{l}\text { Educação básica, } \\
\text { superior, etc. }\end{array}$ \\
\hline Currículo+ & $\begin{array}{l}\text { http://curriculomais.educaca } \\
\text { o.sp.gov.br/ }\end{array}$ & $\begin{array}{l}\text { Educação básica e } \\
\text { fundamental. }\end{array}$ \\
\hline Educopédia & $\begin{array}{l}\text { http://www.educopedia.co } \\
\text { m.br/ }\end{array}$ & $\begin{array}{l}\text { Educação básica e } \\
\text { fundamental. }\end{array}$ \\
\hline Escola Digital & http://escoladigital.org.br/ & $\begin{array}{l}\text { Educação básica, } \\
\text { fundamental e Média. }\end{array}$ \\
\hline $\begin{array}{l}\text { Portal do } \\
\text { Professor }\end{array}$ & $\begin{array}{l}\text { http://portaldoprofessor.me } \\
\text { c.gov.br/index.html }\end{array}$ & $\begin{array}{l}\text { Educação básica, } \\
\text { fundamental, média e } \\
\text { técnica. }\end{array}$ \\
\hline
\end{tabular}

Fonte: criada pelos autores

Alguns sites de buscas possuem informações sobre os tipos de licenças creative commons disponíveis em seus materiais, sites como Flickr (compartilhamento de imagens https://www.flickr.com/), Youtube (compartilhamento de vídeos - https://www.youtube.com/), Google (buscador de imagens, sites, etc. - https://www.google.com.br/), Vimeo (compartilhamento de vídeos - https://vimeo.com/) e outros, possuem buscas avançadas onde o professor poderá buscar por materiais licenciados com o tipo de uso necessário para seu contexto.

\section{CONCLUSÃO}

Notamos que o termo Educação Aberta, é um termo genérico, cujo uso surgiu na década de 70, para tratar e descrever práticas educacionais abertas. Neste contexto, REA compreende a disponibilização de material, devidamente licenciado, e que pode ser uma alternativa viável para o desenvolvimento colaborativo de conteúdos abertos, e disponibilização de cursos e objetos de aprendizagem.

Porém, precisamos ir além da disponibilização de conteúdos educacionais, apoiando o estudante, por meio de práticas pedagógicas de ensino e aprendizagem, à distância ou presencial, com uso das tecnologias. 
Necessitamos de políticas públicas que incentivem e apoiem o uso dos REA, conscientizando os professores da importância do compartilhamento de seus materiais de ensino.

\section{REFERÊNCIAS}

COMMONS, Creative. Sobre As Licenças A função das nossas licenças. Disponível em: <https://creativecommons.org/licenses/?lang=pt_BR>. Acesso em: 09 jul. 2016.

DUTRA, Renato Luís de Souza; TAROUCO, Liane Margarida Rockenbach. Recursos Educacionais Abertos (Open Educational Resources). Disponível em: <http://www.cinted.ufrgs.br/ciclo9/artigos/4fRenato.pdf>. Acesso em: 06 jul. 2016.

EDUCAÇÃO ABERTA. O que é REA. Recursos Educacionais Abertos (REA): Um caderno para professores. Campinas, SP. Disponível em: <http://www.educacaoaberta.org/wiki>. Acesso em: 21 abr. 2016.

GITAHY, Raquel Rosan Christino et al. RECURSOS EDUCACIONAIS ABERTOS: UMA PRÁTICA POSSÍVEL NA PÓSGRADUAÇÃO. Colloquium Humanarum, Presidente Prudente, v. 12, n. , p.14901497, dez. 2015

LESSIG, L. Cultura Livre: como a grande mídia usa a tecnologia e a lei para barrar a criação cultural e controlar a criatividade. São Paulo: Trama, 2005. Disponível em:

https://www.ufmg.br/proex/cpinfo/educacao/docs/10d.pdf. Acesso em: 06 jul. 2016.

PESCE, Lucila; OLIVEIRA, Maria Olívia de Matos. Educação e cultura Midiática. 2012. Pag. 65. Disponível em: <http://eduneb.uneb.br/wpcontent/uploads/2012/12/Educacao_e_Cultura_Midiatica_Volume_II.pdf>. Acesso em: 21 abr. 2016.

ROSSINI, Carolina Almeida Antunes. Green-Paper: The State and Challenges of OER in Brazil: From Readers to Writers? 2010. Disponível em:

<http://papers.ssrn.com/sol3/papers.cfm?abstract_id=1549922>. Acesso em: 09 jul. 2016.

ROSSINI, Carolina; SANTANA, Bianca; PRETTO, Nelson de Luca. RECURSOS EDUCACIONAIS ABERTOS: práticas colaborativas e políticas públicas. 2012. Disponível em: <http://www.livrorea.net.br/livro/home.html>. Acesso em: 21 abr. 2016.

SANTOS, Andreia Inamorato dos. EDUCAÇÃO ABERTA: histórico, práticas e o contexto dos recursos educacionais abertos. Disponível em: <http://www.artigos.livrorea.net.br/2012/05/educacaoaberta-historico-praticas-e-o-contexto-dos-recursos-educacionais-abertos/>. Acesso em: $21 \mathrm{abr}$. 2016.

SANTOS, Andreia Inamorato dos. Recursos Educacionais Abertos no Brasil: O Estado da Arte, Desafios e Perspectivas para o Desenvolvimento e Inovação. 2013. Disponível em: <http://cetic.br/media/docs/publicacoes/8/rea-andreia-inamorato.pdf>. Acesso em: 21 abr. 2016. SEBRIAM, Débora. Entrevista sobre Recursos Educacionais Abertas, publicada no Portal de Educação e Tecnologia do Instituto Ayrton Senna. Disponível em: <http://www.rea.net.br/site/debora-sebriam-3/>. Acesso em: 22 abr. 2016.

SILVA, Robson Santos da. Objetos de Aprendizagem para Educação a Distância. São Paulo: Novatec, 2013. 
VERGARA, Sylvia Constant. Projetos e relatórios de pesquisa em administração. São Paulo: Atlas, 1998.

VENTURINI, Jamila. RECURSOS EDUCACIONAIS ABERTOS NO BRASIL: o campo, os recursos e sua apropriação em sala de aula . Vol. 11. São Paulo : Ação Educativa, 2014. Disponível em: <https://www.academia.edu/9786376/Recursos_educacionais_abertos_no_Brasil_o_campo_os_r ecursos_e_sua_apropria\%C3\%A7\%C3\%A3o_em_sala_de_aula>. Acesso em: 21 abr. 2016.

VENTURINI, Jamila. Recursos Educacionais Abertos: uma mudança de paradigma. Disponível em: <https://pt.wikiversity.org/wiki/Recursos_Educacionais_Abertos:_uma_mudança_de_paradigma>. Acesso em: 22 abr. 2016 